\title{
Enlightenment Now, the Case for Reason, Science, Humanism, and Progress
}

\author{
Steven Pinker \\ (New York, Viking Penguin House, 2018)
}

Pinker es un reconocido psicólogo de origen canadiense y profesor de Harvard. En este libro el autor corona una serie de artículos en los que descalifica a los críticos de la sociedad contemporánea, principalmente a los llamados liberales o progresistas en los Estados Unidos. La estructura del libro es relativamente simple, ya que expone 75 gráficas para demostrar que hay una evolución en la calidad de vida de los habitantes del planeta. El corolario es que vivimos en la mejor época de la humanidad, como dice el epígrafe del libro con una cita de un discurso de Obama.

En la primera parte del libro («Enlightenment») Pinker sitúa de manera simplista a la llustración como un grupo de «pensadores que creían que existía una naturaleza humana y esta puede ser estudiada científicamente» (p. 10). El primer problema es que autores tan disímiles como Hume y Kant no coincidían en la noción de lo humano ni de ciencia. La llustración creía en el progreso, afirma Pinker, sin embargo, su noción de progreso es más cercana a la del positivista Auguste Comte.

He aquí la gran debilidad del libro, la segunda parte (16 capítulos) despliega su argumento central: la evolución lineal y comprobable estadísticamente del progreso. La misma historia ha refutado la idea del progreso, decía Octavio Paz (1990). En su capítulo 4 («Progressophobia»), Pinker supone que el pesimismo de los intelectuales (p. 49) y el tono negativo de los medios (figura 4.1) tiene como resultado «que no se conozca el espectacular progreso en cada medida del bienestar humano» (p. 52).

De esta manera expone en el capítulo 5 («Life») los indicadores que efectivamente muestran un aumento constante en la esperanza de vida y la disminución de la mortalidad infantil y maternal. Asimismo muestra (en el capítulo 6, "Health») la disminución de enfermedades como la malaria. Pero ese capítulo es cuestionable en la medida en que no muestra las enfermedades en aumento como la diabetes y el problema del sobrepeso, generados por las condiciones sociales que aplaude en el capítulo siguiente, como el aumento del consumo de calorías per cápita (p. 70).

En cuanto a la riqueza (capítulo 8), Pinker celebra el aumento del PIB y la disminución de la pobreza extrema en el mundo, principalmente en Asia. Al inicio del capítulo sobre inequidad, Pinker habla de una «obsesión» de los medios y una creencia «convencional» sobre la equidad. Agrega que la inequidad ha sido un reclamo de la izquierda, pero que en las elecciones de Estados Unidos en 2016 los demócratas como Sanders reclamaban mayor equidad social, lo mismo que D. Trump, por lo que «el cinismo compartido» de ambos partidos llevó al poder a Trump (p. 97). Aquí Pinker no ofrece evidencias de esta suposición errónea, según la cual las falsas reivindicaciones de desigualdad social llevaron a la presidencia a un ala radical republicana. Como psicólogo, Pinker debería conocer los mecanismos psicosociales que contribuyeron a una tal victoria. Los grupos conservadores estadounidenses explotaron un viejo sentimiento antiinmigrante y una noción identitaria excluyente (Rangel, 2018). Como 
consecuencia de esta tendencia conservadora, las expresiones racistas se han acentuado en los Estados Unidos.

A pesar del discurso de Pinker, las mismas gráficas que presenta (9.1 y 9.2, pp. 104 y 105) muestran que la inequidad en el mundo se ha incrementado. El autor trata de relativizar este fenómeno, argumentando que la pobreza ha disminuido y el consumo ha aumentado. Sostiene que gracias a Walmart los consumidores estadounidenses han ahorrado mucho dinero (p. 117). Sin embargo, Pinker elude lo evidente, que en la dinámica global se acentúan las desigualdades entre los países del norte y del sur justamente en beneficio de las grandes compañías transnacionales como Walmart. Esta desigualdad entre países ricos y pobres constituye un desafío de justicia global, como señala el intelectual francés Alain Renaut (2013).

En el capítulo 10 sobre el medio ambiente, Pinker se enfrenta a una tarea difícil: probar que el medio ambiente ha mejorado con el progreso. Sus esfuerzos son vanos, a pesar de presentar gráficas sobre el incremento de áreas protegidas (10.6) y la disminución de las emisiones contaminantes (p. 129). Sus mismas gráficas muestran que la deforestación es rampante (p. 131), y que las emisiones de $\mathrm{CO}_{2}$ han aumentado (p. 144). Ciertamente tiene razón al señalar que la energía nuclear, a la cual se oponen muchos ambientalistas, reduce las emisiones de $\mathrm{CO}_{2}$ (p. 146). Sin embargo, pretender que existe un consenso mundial para reducir las emisiones de gas con efecto invernadero es ingenuo toda vez que los negacionistas del cambio climático están en el poder en Estados Unidos y comparten su «optimismo condicional», como él lo denomina (p. 154). Como los tecnócratas, Pinker supone que «un crecimiento económico es un imperativo para adaptarse al cambio climático» (p. 142). No obstante, el crecimiento económico espectacular de China e India muestran lo contrario: índices extremos de contaminación. Como señala el ambientalista canadiense David Suzuki, el crecimiento económico no necesariamente responde a las necesidades y aspiraciones de los ciudadanos, como la de mejorar su medio ambiente (Suzuki, 2018).

En el capítulo 11 sobre la paz, las gráficas muestran un descenso en los conflictos entre potencias (p. 157) y batallas (p. 159). Sin embargo, su perspectiva es despolitizada, ya que afirma que conflictos como aquellos por los que los Estados Unidos conquistaron en 1848 el territorio de México «por una deuda no pagada» no sucederían ahora (p. 163). De la misma forma argumenta un progreso de la seguridad mundial con un descenso de los accidentes, el terrorismo y los homicidios en el mundo. Sin embargo, sabemos que en América Latina todos los índices de violencia persisten en la mayoría de los países, Pinker solamente menciona Venezuela a causa del chavismo (p. 171). Es decir, emplea un criterio partidista.

En el capítulo 14 sobre la democracia, Pinker suscribe el discurso conservador de Huntington de la tercera ola de democratización y la noción de Fukuyama del fin de la historia como un consenso de la humanidad (p. 201). Minimiza los autoritarismos actuales, como el de China (p. 204). Afirma que muchos politólogos (no dice cuáles) han señalado que «los electores son conscientes del escaso impacto de su voto, pero no hacen nada para informarse y ajustar su voto» (p. 205). Una vez más, Pinker tuvo la oportunidad de abordar la cuestión de la capacidad de los votantes, como la racionalidad de los electores desde la perspectiva de la psicología política. En cuanto a los derechos humanos, Pinker presenta una cuestionable gráfica en la que indica un progreso de estos derechos en el mundo (p. 208). Esta toma en cuenta la tortura, las muertes extrajudiciales y las desapariciones, precisamente problemas persistentes en buena parte de América Latina. 
Respecto a la igualdad de derechos, Pinker pretende probar que ha disminuido la discriminación y los crímenes de odio (p. 220). Pero afirmar esto en la era Trump es un contrasentido, ya que las mismas cifras oficiales muestran un incremento en crímenes de carácter racista ${ }^{3}$.

En el avance del conocimiento (capítulo 16), Pinker muestra las previsibles gráficas de aumento de escolaridad y alfabetismo en el mundo, pero suscribe la controvertida teoría del aumento del coeficiente intelectual, el llamado efecto Flynn (p. 241). Esto supone una apuesta cuestionable de un psicólogo conocedor de teorías cognitivas modernas.

Al mantener que la calidad de vida de las personas ha mejorado, supone que esto sucede bajo criterios estrictamente materiales, como el hecho de que la gente tiene mayor número de refrigeradores, estufas, lavadoras, etc. (p. 252). ¿Es este un criterio de bienestar humano o de expansión comercial? Además, el hecho de que haya cada vez más gente jubilada no significa que esto mejore su calidad de vida (como él sostiene), ya que la gran mayoría de ellos, sobre todo en América Latina, no cuentan con pensiones suficientes (OIT, 2017).

En el capítulo 18, sobre la felicidad, Pinker acepta que esta no ha crecido, a pesar de que el sentimiento de soledad ha disminuido, así como la tasa de suicidio (p. 279). La felicidad de la población estadounidense se ha estancado a pesar del progreso material, concede. Hay que reconocer que Pinker hace aquí una incursión psicológica para abordar la relatividad de la felicidad, como la noción de Baumeister de vida significativa (p. 267). Entonces resulta inexplicable que Pinker recurra, como su «análisis favorito», al de los economistas Stevenson y Wolfers, que hace una correlación estadística entre el promedio de ingreso y la satisfacción de vida (gráfica 18-1). De esta forma, los países ricos se ubican al frente y se presenta así a la economía como el fin último del progreso que acarrea la felicidad. El capítulo 19, sobre peligros existenciales, hace referencia a la amenaza nuclear, que, a pesar de la disminución de los arsenales, persiste.

Pinker hace una recapitulación del progreso (capítulo 20) en el que confronta con el populismo autoritario de la actualidad, representado por Donald Trump. No obstante, esta crítica justa se diluye debido a que en todo su libro presentó a quienes señalan contradicciones de la economía y la política actual como los enemigos del progreso. Una de las contradicciones del libro es suponer que sigue una "ciencia objetiva», pero al mismo tiempo el autor encuentra artificios para denostar a sus adversarios. Por ejemplo, es bien conocida su oposición a Chomsky y en el libro solamente lo nombra para mencionar que Bin Laden tenía un libro de ese autor (p. 443). En lugar de lanzar este dardo pueril, el libro hubiera ganado más si Pinker hubiese debatido los argumentos de Chomsky. Por ejemplo, para este autor el progreso no se logra como regalos desde arriba, sino a partir de luchas desde abajo (Chomsky, 1993).

En el capítulo 21 («Reason») retoma del abogado Dan Kahan la suposición según la cual la gente toma algunas creencias como símbolos de «pertenencia cultural» y se identifica con subculturas o tribus (p. 357). Más allá de la solidez teórica de este principio, Pinker hace un uso cuestionable, pues descalifica tanto las teorías conspiracionistas como las reivindicaciones de una sociedad más igualitaria. De esta manera pretende que «cuando los temas no son politizados, la gente puede ser racional» (p. 381). No obstante, esta despolitización merma su análisis, pues incluso supone que el documental de Al Gore, An Inconvenient Truth,

3 FBI (2018), Hate Crime Statistics 2017. 
afectó al movimiento ambientalista por asociarlo a los demócratas. Esta objeción ha sido más bien un pretexto de los republicanos, ya que los políticos de cualquier filiación deben defender las evidencias científicas sobre las condiciones reales del medio ambiente.

En esta lógica, su alegato para defender la ciencia (capítulo 22) sería inútil justamente ante la embestida de los grupos conservadores en Estados Unidos. Como el mismo Pinker menciona, los políticos de derecha muestran una falta de respeto hacia la ciencia (p. 387). Entonces no se trata de una simple «pertenencia cultural», se trata de un problema político en el que grupos fundamentalistas controlan las políticas públicas ambientales y de la ciencia desde el Gobierno federal y el Congreso estadounidense.

En su capítulo final (23), Pinker hace una apología del humanismo en la que acertadamente hace apelación a su dimensión moral, y en este sentido critica el amoralismo de Nietzsche (p. 445). El autor hace una incursión, quizá innecesaria, sobre las religiones en la actualidad, y se pregunta si estas pueden contribuir al humanismo (p. 432). Pero él mismo responde que las religiones pueden ser utilizadas de manera clientelar, como sucedió con los evangélicos en la elección de Trump. Supone que los dictadores son los enemigos del humanismo por violar los derechos humanos, pero después de leer su libro, el lector puede preguntarse si el progreso material y económico que defiende con docenas de gráficas produce naturalmente el humanismo que reclama.

En suma, el libro es contradictorio y tiene una narrativa maniquea y partidista. No logra armar un cuerpo teórico que apuntale una agenda progresista porque justamente ataca los movimientos progresistas que reclaman un mejor medio ambiente y una sociedad más igualitaria y justa. Pinker supone que estos movimientos son los enemigos del progreso, sin embargo, estos cuestionan y critican las contradicciones que su «optimismo» pasa por alto. Trata de defender la llustración y la razón con gráficas convencionales, manteniendo que la Ilustración del siglo XVIII fue ante todo, como decía Octavio Paz, una crítica social (Paz, 1988). Asumir que vivimos en la cúspide del progreso humano, como supone Pinker, tiene consecuencias claramente conservadoras. El papel de los intelectuales es más bien el de exponer las mentiras y contradicciones del poder (Chomsky, 2017). Desde América Latina se constatan las evidentes contradicciones de este discurso del progreso.

por Hugo RANGEL TORRIJO

Universidad de Guadalajara / UQAM

hugo.rangel@mail.mcgill.ca

\section{Bibliografía}

Chomsky, Noam (1993). Secrets, Lies and Democracy. Tucson: Odonian Press.

Chomsky, Noam (2017). It is the Responsability of Intellectuals to Speak the Truth and to Expose Lies. New York: The New Press.

OIT (2017). Informe Mundial sobre la Protección Social 2017-2019.

Paz, Octavio (1988). «¿Es moderna la literatura hispanoamericana?». Conferencia inaugural del XXVII Congreso del Instituto Internacional de Literatura Iberoamericana. México.

Paz, Octavio (1990). Nobel Lecture. NobelPrize.org. Nobel Media AB 2018. Thu. 15 Nov 2018. Disponible en: https://www.nobelprize.org/prizes/literature/1990/paz/25350-octavio-paz-nobel-lecture-1990/ 
Rangel Torrijo, Hugo (2018). «The Conservative Discourse Behind the US-Mexico Border Wall vs. Co-operation for Cross-Border Regional Development». Revue Représentations dans le monde anglophone, 1.

Renaut, Alain (2013). Un monde juste est-il possible? Paris: Stock.

Suzuki (2018). What is Economic Success? David Suzuki Foundation. Disponible en: https://davidsuzuki.org/ expert-article/what-is-economic-success-imagining-a-canada-beyond-growth/

\title{
El rigor de lo cualitativo. Las obligaciones empíricas de la interpretación socioantropológica
}

\author{
Jean-Pierre Olivier de Sardan \\ (Madrid, Centro de Investigaciones Sociológicas, 2018)
}

Este libro, que acaba de ver la luz en 2018, editado por el Centro de Investigaciones Sociológicas, tiene el gran reto de entrar en el debate sobre la validez y rigurosidad de la investigación social cualitativa. Desde el inicio del trabajo hasta la escritura de los resultados, pasando por todo tipo de cuestiones metodológicamente pertinentes del proceso de inmersión cualitativa en el campo, el libro supone una gran aportación para aquellos investigadores que investiguen de forma cualitativa cualquier aspecto de la realidad social. En ese sentido, la obra tiene la virtud (aunque no el anhelo) de servir de hoja de ruta para el trabajo de campo, al poner de relieve dimensiones de este que han de ser cuidadosamente objetivadas por quien lo practica. Declarándose heredero de las tradiciones antropológicas y sociológicas más apegadas al trabajo de campo etnográfico, Jean-Pierre Olivier de Sardan (politólogo, sociólogo y antropólogo francés vinculado a la École des Hautes Études en Sciences Sociales en Marsella) elabora este libro sin pretensiones de manual a través del conjunto de prácticas empíricas que, en su análisis, deben rodear todo ejercicio de interpretación socioantropológica. Un concepto que señala una tradición de investigación metodológica que el autor vincula, por un lado, a las etnografías urbanas de la Escuela de Chicago en los años veinte del siglo XX (sociología cualitativa), y por otro, a las etnologías desarrolladas de forma pionera por Malinowski (antropología).

El libro se compone de ocho capítulos independientes, a través de los cuales el autor va desgranando las diferentes aristas del trabajo de campo, señalando los potenciales sesgos que amenazan el rigor de la investigación cualitativa y, como no podía ser de otra manera, posicionándose en una determinada forma de entender la reflexividad científica y el desarrollo del rigor de ese trabajo. De hecho, en la propia Introducción queda clara su defensa de una "socioantropología no culturalista» que sea capaz de contextualizar sus hallazgos, sin dejarse llevar por los cantos de sirena posmodernos (p. 21). En esta parte introductoria es donde señala la importancia del «pacto etnográfico» a la hora de entender y definir la base del rigor cualitativo, ya que todo investigador etnográfico está obligado a ejercer un «efecto de realidad" cuando describe (o transcribe) una situación fruto de una observación: "el "os garantizo que allí eso es así" es nuestro argumento de venta» (p. 19). A partir de esta intro- 